TITLE:

\title{
Dopant Site Occupancy and Chemical Expansion in Rare Earth- Doped Barium Zirconate
}

$\operatorname{AUTHOR}(S)$ :

Han, Donglin; Shinoda, Kozo; Uda, Tetsuya

\section{CITATION:}

Han, Donglin ...[et al]. Dopant Site Occupancy and Chemical Expansion in Rare EarthDoped Barium Zirconate. Journal of the American Ceramic Society 2013, 97(2): 643-650

\section{ISSUE DATE:}

2013-12-12

URL:

http://hdl.handle.net/2433/197460

\section{RIGHT:}

This is the peer reviewed version of the following article: Han, D., Shinoda, K., Uda, T. (2014). Dopant Site Occupancy and Chemical Expansion in Rare Earth-Doped Barium Zirconate. Journal of the American Ceramic Society, 97: 643-650, which has been published in final form at http://dx.doi.org/10.1111/jace.12681; This is not the published version. Please cite only the published version.; この論文は出版社版でありません。引用の際には出版社版をご確認で利用ください。 
To: Journal of the American Ceramic Society

\section{Dopant Site Occupancy and Chemical Expansion in Rare Earth-Doped Barium Zirconate}

Donglin Han ${ }^{a^{*}}$, Kozo Shinoda ${ }^{b}$, Tetsuya Uda ${ }^{a^{*}}$

${ }^{a}$ Department of Materials Science and Engineering, Kyoto University,

Yoshida Honmachi, Sakyo-ku, Kyoto 606-8501, Japan

b Institute of Multidisciplinary Research for Advanced Materials, Tohoku University,

Katahira 2-1-1, Aoba-ku, Sendai 980-8577, Japan

* Corresponding author: Donglin Han (han.donglin.8n@kyoto-u.ac.jp)

and Tetsuya Uda (materials_process@aqua.mtl.kyoto-u.ac.jp)

TEL: +81-75-753-5445, FAX: +81-75-753-5284 


\section{Abstract}

Rare earth-doped $\mathrm{BaZrO}_{3}$ is a very attractive material in electrochemical applications due to its proton conductive property. In this work, powder X-ray diffraction patterns of $\mathrm{BaZr}_{0.8} \mathrm{M}_{0.2} \mathrm{O}_{3-\delta}(\mathrm{M}$ $=\mathrm{Sc}$, Eu, Sm, Dy) were collected using synchrotron radiation, and also using characteristic X-ray of $\mathrm{Cu} \mathrm{K \alpha}$ in dry and wet atmospheres at high temperature. Then a combined interpretation of the diffraction patterns was established by using Rietveld refinement. The results revealed that an obvious lattice expansion was observed for $\mathrm{BaZr}_{0.8} \mathrm{M}_{0.2} \mathrm{O}_{3-\delta}\left(\mathrm{M}=\mathrm{Sc}\right.$, Eu, Sm, Dy) in wet $\mathrm{O}_{2}$ compared with the case in dry condition, indicating a chemical expansion effect on lattice volume by incorporating water into lattice. $\mathrm{Eu}, \mathrm{Sm}$ and Dy cations occupied both $\mathrm{A}$ and B-sites of $\mathrm{BaZrO}_{3}$ crystalline lattice, whereas Sc cations were determined to occupy B-site only. These results indicate clearly an increasing tendency towards A-site occupation for the rare earth cations in $\mathrm{BaZrO}_{3}$ with an increasing radius.

Keywords: rare earth; barium zirconate; site occupancy; perovskite; proton conductor; synchrotron radiation 


\section{Introduction}

Rare earth-doped Barium zirconate $\left(\mathrm{BaZrO}_{3}\right)$ with a perovskite-type $\left(\mathrm{ABO}_{3}\right)$ structure attracts an increasing attention in recent years due to its specific property of proton conduction. For example, trivalent yttrium (Y) doped $\mathrm{BaZrO}_{3}$ exhibits a high protonic conductivity exceeding $10^{-2} \mathrm{~S} \mathrm{~cm}^{-1}$ at around $600{ }^{\circ} \mathrm{C}$ in a humid atmosphere ${ }^{1,2}$. Conductivity of $\mathrm{BaZrO}_{3}$ doped with dysprosium (Dy) was remarkably high in a humid reducing atmosphere, but dropped dramatically in an oxidizing one ${ }^{3}$, due to a change in oxidization state of Dy from trivalent to tetravalent ${ }^{4}$. Conventionally speaking, rare earth cations are believed to prefer B-site occupation, and substitute partially tetravalent $\mathrm{Zr}$ cations. However, recent works on Y-doped $\mathrm{BaZrO}_{3}{ }^{5-7}$ revealed that $\mathrm{Y}$ also occupied A-site to substitute divalent $\mathrm{Ba}$ cations. Different site occupations of rare earth cations induce totally different reactions in defect chemistry. ${ }^{3,8}$ And significant influence on the protonic conductivity is expected from the site occupancy of rare earth. In addition, several perovskite-type proton conductors, such as Yb-doped $\mathrm{BaCeO}_{3}{ }^{10}$, Y-doped $\mathrm{BaCeO}_{3}{ }^{11}$, Y-doped $\mathrm{BaZrO}_{3}{ }^{12}$, and In-doped $\mathrm{BaZrO}_{3}{ }^{13}$, exhibit a lattice expansion when they are exposed to moisture, due to a chemical expansion effect induced by water incorporation ${ }^{12}$. Knowledge of such property of the perovskite-type proton conductors is important when interpreting the information in diffraction patterns. ${ }^{7}$

This study confirms the chemical expansion of Sc, Eu, Sm, and Dy-doped $\mathrm{BaZrO}_{3}$ with high temperature X-ray diffraction (HT-XRD) measurements performed in dry and wet atmospheres. A 
more precise analysis of diffraction patterns collected by synchrotron radiation is demonstrated by taking the coexistence of hydrated and dehydrated phases into consideration, and gives a quantitative analysis on the site occupancy of Sc, Eu, Sm, and Dy in $\mathrm{BaZrO}_{3}$. Finally, this work presents a further discussion on the change of structural properties of $\mathrm{BaZrO}_{3}$, when various dopants are doped.

\section{Experimental}

\section{(1) Material preparation}

Samples with nominal composition of $\mathrm{BaZr}_{0.8} \mathrm{M}_{0.2} \mathrm{O}_{3-\delta}(\mathrm{M}=\mathrm{Sc}$, Eu, Sm, Dy) were prepared by a conventional solid state reaction method. Starting materials of $\mathrm{BaCO}_{3}, \mathrm{ZrO}_{2}$, and $\mathrm{M}_{2} \mathrm{O}_{3}(\mathrm{M}=\mathrm{Sc}$, $\mathrm{Eu}, \mathrm{Sm}, \mathrm{Dy})$ were mixed at the desired ratios and ball-milled for $24 \mathrm{~h}$. Then, mixtures were pressed into pellets under 9.8 $\mathrm{MPa}$ and heat-treated at $1000{ }^{\circ} \mathrm{C}$ for $10 \mathrm{~h}$. After ball-milling for $10 \mathrm{~h}$, samples were pressed into pellets under 9.8 MPa again, and heat-treated at $1300{ }^{\circ} \mathrm{C}$ for $10 \mathrm{~h}$. After that, samples were ball-milled for $24 \mathrm{~h}$ and mixed with an organic binder solution consisting of water, polyvinyl alcohol, glycerin, and ethanol. Mixtures were then pressed into pellets at $392 \mathrm{MPa}$, and subsequently heat-treated at $600{ }^{\circ} \mathrm{C}$ for $8 \mathrm{~h}$ to remove the binder solution. At last, the pellets were heated up to $1600{ }^{\circ} \mathrm{C}$, then kept for $24 \mathrm{~h}$, and finally quenched at room temperature in ambient atmosphere. 


\section{(2) Measurements}

Chemical compositions of the samples with the nominal compositions of $\mathrm{BaZr}_{0.8} \mathrm{Sc}_{0.2} \mathrm{O}_{3-\delta}$, $\mathrm{BaZr}_{0.8} \mathrm{Eu}_{0.2} \mathrm{O}_{3-\delta}, \mathrm{BaZr}_{0.8} \mathrm{Sm}_{0.2} \mathrm{O}_{3-\delta}$ and $\mathrm{BaZr}_{0.8} \mathrm{Dy}_{0.2} \mathrm{O}_{3-\delta}$ were determined to be $\mathrm{Ba}_{1.00} \mathrm{Zr}_{0.81} \mathrm{Sc}_{0.19} \mathrm{O}_{3-\delta}$, $\mathrm{Ba}_{0.96} \mathrm{Zr}_{0.82} \mathrm{Eu}_{0.18} \mathrm{O}_{3-\delta}, \mathrm{Ba}_{0.98} \mathrm{Zr}_{0.81} \mathrm{Sm}_{0.19} \mathrm{O}_{3-\delta}$ and $\mathrm{Ba}_{0.97} \mathrm{Zr}_{0.81} \mathrm{Dy}_{0.19} \mathrm{O}_{3-\delta}$, respectively, by inductively coupled plasma atomic emission spectroscopy (ICP-AES) with SPS4000 (Seiko Instruments Inc., Chiba, Japan). Microstructures were observed by scanning electron microscopy (SEM) with VE-7800 (Keyence Co., Osaka, Japan). Local compositions of crystal grains were point-analyzed by energy dispersion X-ray spectroscopy (SEM-EDS) with Genesis-XM2 (EDAX, Mahwah, USA), and calibrated based on the assumption that the average compositions determined by SEM-EDS area-analysis were equal to those measured by ICP-AES ${ }^{14}$.

Powder XRD measurements were performed at the SPring-8 synchrotron radiation facility (Hyogo, Japan) by using beamline BL19B2 with X-ray energy of $17.026 \mathrm{keV}$. High temperature X-ray diffraction (HT-XRD) measurements were performed using $\mathrm{Cu} K \alpha$ radiation with X'Pert-ProMPD (PANalytical, Almelo, Netherland) equipped with a HTK 1200N high-temperature chamber (Anton Paar, Graz, Austria). Atmospheres of dry $\mathrm{O}_{2}$, dry Ar, and wet $\mathrm{O}_{2}$ with a partial pressure of water vapor of 0.0312 atm were used during the HT-XRD measurements. The wet $\mathrm{O}_{2}$ atmosphere was achieved by bubbling oxygen through water at room temperature. Temperature profiles were the same as that in our previous work ${ }^{12}$, and the average heating and cooling rates were estimated to be 1.38 and $1.06{ }^{\circ} \mathrm{C} / \mathrm{min}$, respectively. Rietveld refinement was carried out by utilizing a commercial 
software TOPAS (Bruker AXS GmbH, Karlsruhe, Germany).

\section{Results}

(1) XRD measurements using synchrotron radiation

Diffraction patterns collected by using synchrotron radiation are shown in Fig. 1 with the (031) diffraction peaks highlighted in insets. The (031) diffraction peak of $\mathrm{BaZr}_{0.8} \mathrm{Sm}_{0.2} \mathrm{O}_{3-\delta}$ was obviously asymmetric and broad in shape (Fig. 1(b)). And all the other diffraction peaks of $\mathrm{BaZr}_{0.8} \mathrm{Sm}_{0.2} \mathrm{O}_{3-\delta}$ exhibited a similar appearance. Shape of the diffraction peaks of Sc, Eu, and Dy-doped $\mathrm{BaZrO}_{3}$ showed a better symmetry than that of the Sm-doped sample.

\section{(2) Microstructure observation and composition analysis}

From SEM images of fractured cross-sections, as shown in Fig. 2, dense microstructures were obtained for all the samples. Average grain sizes of Sc, Eu, and Sm-doped samples were roughly estimated to be around $1 \mu \mathrm{m}$ from the SEM images. Larger grains were observed in the Dy-doped sample with an average grain size over $2 \mu \mathrm{m}$. In order to check the large-scale homogeneity, SEM-EDS measurements were performed on the fractured surfaces to determine compositions of single grains. Since the effective spot size of SEM-EDS is about $1 \mu \mathrm{m}$, comparable with the grain size of Sc, Eu, and Sm-doped samples, but smaller than that of the Dy-doped one, we consider that sufficient precision can be obtained here by using SEM-EDS. Fig. 3 shows the compositions of 
single grains determined by SEM-EDS, and also the total compositions measured by ICP-AES. For all the four samples, no obvious dispersion in the composition of single grains was observed. And the average values of the single grain compositions almost coincide with the average bulk compositions determined by ICP-AES.

\section{(3) Rietveld refinement}

In order to determine the site occupancy of Sc, Eu, Sm and Dy in $\mathrm{BaZrO}_{3}$, Rietveld refinements were performed to simulate the XRD patterns collected using synchrotron radiation. Since during the SEM-EDS measurements, we did not observe any other compositionally different phase besides the ones with the compositions close to the average bulk compositions determined by ICP-AES, so firstly, existence of a single perovskite phase was assumed for all the four samples. A single cubic perovskite ( $P m \overline{3} m$ ) structure model whose composition was assigned to be the bulk composition determined by ICP-AES was used for simulations. As shown in Fig. 4, although values of $R_{\mathrm{wp}}$ lower than $10 \%$ was obtained for Sc, Eu and Dy-doped $\mathrm{BaZrO}_{3}$, a large $R_{\mathrm{wp}}$ of $14.13 \%$ was achieved when simulating the XRD pattern of $\mathrm{BaZr}_{0.8} \mathrm{Sm}_{0.2} \mathrm{O}_{3-\delta}$, and the calculated profile deviated obviously from the observed profile (Fig. 4(b)). We attempted to take the possibility of structural distortion due to tilting of $\mathrm{Zr}(\mathrm{Sm}) \mathrm{O}_{6}$ octahedra into consideration, and used a tetragonal perovskite-type $(P 4 / \mathrm{mbm})$ structure model suggested by Giannici et al. ${ }^{9}$, but found that this structure did not fit well because $R_{\mathrm{wp}}$ was still as high as $16.24 \%$. Since all the diffraction peaks in the 
pattern of $\mathrm{BaZr}_{0.8} \mathrm{Sm}_{0.2} \mathrm{O}_{3-\delta}$ exhibited asymmetric appearances in the same way, it should not be simply attributed to a structural distortion. A similar phenomenon was also observed in Y-doped $\mathrm{BaZrO}_{3}{ }^{7,9}$, and we recently found that it was due to an overlapping of diffraction patterns of dehydrated and hydrated phases. The hydrated phase has a larger lattice constant than that of the dehydrated one due to water incorporation ${ }^{7}$. Since $\mathrm{BaZr}_{0.8} \mathrm{Sm}_{0.2} \mathrm{O}_{3-\delta}$ was available for water incorporation in a humid atmosphere ${ }^{3}$, it is highly possible that such asymmetric diffraction peak shape of $\mathrm{BaZr}_{0.8} \mathrm{Sm}_{0.2} \mathrm{O}_{3-\delta}$ comes from a coexistence of hydrated and dehydrated phases as well. Thereby, two cubic perovskite ( $\mathrm{Pm} \overline{3} \mathrm{~m}$ ) structure models both with the composition of $\mathrm{Ba}_{0.98} \mathrm{Zr}_{0.81} \mathrm{Sm}_{0.19} \mathrm{O}_{3-\delta}$, the same as the average bulk composition determined by ICP-AES, were assumed to simulate the diffraction patterns of the hydrated phase (relatively larger lattice constant) and dehydrated phase (relatively smaller lattice constant). As shown in Fig. 5, the calculated profile was close to the observed profile of $\mathrm{BaZr}_{0.8} \mathrm{Sm}_{0.2} \mathrm{O}_{3-\delta}$, and the value of $R_{\mathrm{wp}}$ was significantly lowered to $6.60 \%$, indicating an improvement in fitting quality. In addition, compared with Sm-doped $\mathrm{BaZrO}_{3}$, higher capability for water incorporation has been confirmed in Sc, Eu and Dy-doped $\mathrm{BaZrO}_{3}{ }^{3,4,15}$, so a coexistence of hydrated and dehydrated phases was highly possible for these samples. We therefore simulate the XRD patterns of Sc, Eu and Dy-doped $\mathrm{BaZrO}_{3}$ with the same method by using two cubic perovskite ( $P m \overline{3} m$ ) structure models. The profiles of Rietveld refinements are shown in Fig. 6 - 8, and the results are summarized in Table 1. It was found that the values of $R_{\mathrm{wp}}$ were lowered to $6.74 \%, 5.45 \%$ and $7.54 \%$ for Sc, Eu and Dy-doped samples, 
respectively, indicating that fitting qualities were further improved. And referring to site occupancy (see Table 1), it was determined that all Sc cations occupied the B-site, whereas Eu, Sm and Dy partitioned over the A and B-sites.

\section{(4) HT-XRD measurement}

XRD patterns of $\mathrm{BaZr}_{0.8} \mathrm{M}_{0.2} \mathrm{O}_{3-\delta}(\mathrm{M}=\mathrm{Sc}$, Eu, Sm, Dy), which were collected during cooling from $1000{ }^{\circ} \mathrm{C}$ to $30{ }^{\circ} \mathrm{C}$ under various atmospheres in HT-XRD measurements, were simulated using Rietveld refinement to determine lattice constants, as shown in Fig. 9. Increase in lattice constant was observed clearly for all the four samples when the atmosphere was altered from dry $\mathrm{O}_{2}$ to wet $\mathrm{O}_{2}$. In addition, for Sc, Eu and Sm-doped $\mathrm{BaZrO}_{3}$, there is no obvious difference in the lattice constant in dry $\mathrm{O}_{2}$ and dry Ar. But the lattice constant of $\mathrm{BaZr}_{0.8} \mathrm{Dy}_{0.2} \mathrm{O}_{3-\delta}$ in dry $\mathrm{O}_{2}$ was significantly lower than that in dry Ar. Table 2 gives a list of the lattice constants at $30^{\circ} \mathrm{C}$ in various atmospheres.

\section{Discussion}

The phenomenon that larger lattice constants were obtained in wet $\mathrm{O}_{2}$ than in dry $\mathrm{O}_{2}$ clearly indicates the chemical expansion by incorporating water molecules into the lattice of $\mathrm{BaZrO}_{3}$ doped with Sc, Eu, Sm and Dy. Due to the reaction for water incorporation (Eq. (1)), some lattice oxide ions with double negative charges $\left(\mathrm{O}_{\mathrm{O}}^{\times}\right)$, and neutral oxide ion vacancies $\left(\mathrm{V}_{\mathrm{O}}^{\bullet \bullet}\right.$ ) were replaced by hydroxide defects with a single negative charge $\left(\mathrm{OH}_{\mathrm{O}}^{\circ}\right)$. And a combined influence is expressed to be the expansion of the lattice volume. 


$$
\mathrm{H}_{2} \mathrm{O}+\mathrm{V}_{\mathrm{O}}^{\bullet \bullet}+\mathrm{O}_{\mathrm{O}}^{\times} \rightarrow 2 \mathrm{OH}_{\mathrm{O}}^{\bullet}
$$

In other perovskite-type proton conductors, such as $\mathrm{Yb}$-doped $\mathrm{BaCeO}_{3}{ }^{10}$, Y-doped $\mathrm{BaCeO}_{3}{ }^{11}$ and $\mathrm{BaZrO}_{3}{ }^{12}$, and In-doped $\mathrm{BaZrO}_{3}{ }^{13}$, similar phenomena were also confirmed. This water incorporation-induced chemical expansion might be a common property of the perovskite-type proton conductors, and the lattice constant of a hydrated phase is larger than that of a dehydrated one. In addition, although there was no obvious difference in the lattice constants of Sc, Eu and Sm-doped samples in dry $\mathrm{Ar}$ and dry $\mathrm{O}_{2}$, the lattice constant of $\mathrm{BaZr}_{0.8} \mathrm{Dy}_{0.2} \mathrm{O}_{3-\delta}$ increased significantly when the atmosphere was altered from dry $\mathrm{O}_{2}$ to dry Ar. It is due to a change of oxidation state of Dy from tetravalent in a reducing atmosphere to trivalent in an oxidizing atmosphere ${ }^{4}$, resulting in an increase in the six-coordinated radius of Dy cations from $0.78 \AA^{16}$ to $0.912 \AA^{17}$, and thereby an expansion of lattice volume.

It is very interesting to make a comparison between the lattice constants calculated by simulating the XRD patterns collected using synchrotron radiation, and those from the HT-XRD measurements using $\mathrm{Cu} \mathrm{K \alpha}$ characteristic X-ray. As summarized in Fig. 10, for $\mathrm{BaZr}_{0.8} \mathrm{Sc}_{0.2} \mathrm{O}_{3-\delta}$ and $\mathrm{BaZr}_{0.8} \mathrm{Eu}_{0.2} \mathrm{O}_{3-\delta}$, very close values were obtained for the lattice constants of their dehydrated phases determined from the synchrotron radiation experiments and HT-XRD measurements in dry $\mathrm{O}_{2}$ at 30 ${ }^{\circ} \mathrm{C}$. But the hydrated phases determined from the synchrotron radiation experiments had smaller lattice constants than those from the HT-XRD measurements in wet $\mathrm{O}_{2}$. Since the samples for synchrotron radiation experiments were finally quenched in air at room temperature after the 
heat-treatment at $1600{ }^{\circ} \mathrm{C}$ to get a quick cooling, even this short exposure to ambient atmosphere was expected to cause the surface layer of the samples to be hydrated. And the difference in lattice constants of hydrated phases determined in synchrotron radiation experiments and HT-XRD measurements is considered to be attributed to the different amount of water incorporated into the samples. Lattice constants of $4.1957 \AA$ and $4.2312 \AA$ should be the values for $\mathrm{BaZr}_{0.8} \mathrm{Sc}_{0.2} \mathrm{O}_{3-\delta}$ and $\mathrm{BaZr}_{0.8} \mathrm{Eu}_{0.2} \mathrm{O}_{3-\delta}$ saturated with water, respectively. But $4.1906 \AA$ and $4.2273 \AA$ are for the partially hydrated ones. The case for $\mathrm{BaZr}_{0.8} \mathrm{Dy}_{0.2} \mathrm{O}_{3-\delta}$ is complicated, because the oxidation state of Dy is very sensitive to oxygen partial pressure in atmosphere ${ }^{4}$. Since the sample was heat-treated at $1600{ }^{\circ} \mathrm{C}$ in $\mathrm{O}_{2}$, but finally quenched in ambient air containing lower oxygen partial pressure, the average oxidation state of Dy in the sample should be intermediate between those obtained in pure $\mathrm{O}_{2}$ and $\mathrm{Ar}$ atmospheres. And therefore, as expected, the lattice constant of the dehydrated phase in $\mathrm{BaZr}_{0.8} \mathrm{Dy}_{0.2} \mathrm{O}_{3-\delta}$ determined from synchrotron radiation experiments was $4.2216 \AA$ (Table 1), intermediate between the values of $4.2119 \AA$ and $4.2223 \AA$ simulated from the XRD patterns collected in dry $\mathrm{O}_{2}$ and dry Ar, respectively (Table 2). And the hydrated phase in the synchrotron radiation experiments has a larger lattice constant $(4.2240 \AA)$ than that determined from the HT-XRD measurements in wet $\mathrm{O}_{2}(4.2148 \AA)$. For $\mathrm{BaZr}_{0.8} \mathrm{Sm}_{0.2} \mathrm{O}_{3-\delta}$, compared to the results obtained from synchrotron radiation, relatively smaller and larger lattice constants were determined for the hydrated and dehydrated phases from the HT-XRD measurements. The reason is not clear, and further investigation is expected in future. 
As given in Table 1, in the samples with a slight Ba-deficiency, Sc was determined to only occupy the B-site, and Eu, Sm, Dy occupied both the A and B-sites. Since a trivalent Sc cation has a six-coordinated radius of $0.745 \AA$, very close to the value of $0.72 \AA$ for a tetravalent $\mathrm{Zr}$ cation ${ }^{17}$. This comparable radius makes Sc very stable in the B-site. However, for trivalent Eu $\left(0.947 \AA{ }^{17}\right)$, Sm $\left(0.958 \AA^{17}\right)$ and Dy $\left(0.912 \AA^{17}\right)$ cations, their six-coordinated radii are obviously larger than that of a tetravalent Zr cation. And even in the samples with only slight Ba-deficiency between 0.02 0.04, Eu, Sm and Dy cations were determined to partition over the A and B-sites. These results clearly indicate an increasing tendency towards A-site occupation of the dopants in $\mathrm{BaZrO}_{3}$ with an increasing cation radius. From the view point of defect chemistry, B-site occupation (Eq. (2)) and A-site occupation (Eq. (3)) of the trivalent dopant cations (M) produces and consumes the oxide ion vacancies, respectively. In our previous work ${ }^{3}$, smaller water content was measured for Sm and Eu-doped $\mathrm{BaZrO}_{3}$, compared with the sample doped with Sc. The A-site occupation of Sm and Eu, which decreases the concentration of oxide ion vacancies, should also be a reason for the lower water content.

$$
\begin{aligned}
& \mathrm{M}_{2} \mathrm{O}_{3}+2 \mathrm{Zr}_{\mathrm{Zr}}^{\times}+\mathrm{O}_{\mathrm{O}}^{\times} \rightarrow 2 \mathrm{M}_{\mathrm{Zr}}^{\prime}+2 \mathrm{ZrO}_{2}+\mathrm{V}_{\mathrm{O}}^{\bullet \bullet} \\
& \mathrm{M}_{2} \mathrm{O}_{3}+2 \mathrm{Ba}_{\mathrm{Ba}}^{\times}+\mathrm{V}_{\mathrm{O}}^{\bullet \bullet} \rightarrow 2 \mathrm{M}_{\mathrm{Ba}}^{\bullet}+2 \mathrm{BaO}+\mathrm{O}_{\mathrm{O}}^{\times}
\end{aligned}
$$

Although chemical expansion of doped $\mathrm{BaZrO}_{3}$ can be regarded to be an evidence for water incorporation, it is not easy to establish a simple correlation between such chemical expansion and proton conductivity. Proton conductivity depends on both the proton concentration and the proton 
mobility, whereas the chemical expansion relies mainly on the proton concentration in the system. But empirically, higher proton concentration benefits the proton conductivity, and also promotes the chemical expansion. Revealing the relationship between the proton concentration and change of lattice volume might be an interesting topic in future.

\section{Conclusions}

Larger lattice constants were calculated for the $\mathrm{BaZr}_{0.8} \mathrm{M}_{0.2} \mathrm{O}_{3-\delta}\left(\mathrm{M}=\mathrm{Sc}\right.$, Eu, Sm, Dy) in wet $\mathrm{O}_{2}$ than dry $\mathrm{O}_{2}$, clearly indicating a chemical expansion effect on lattice volume by incorporating water into lattice. This water incorporation-induced chemical expansion is considered to be a common property of perovskite-type proton conductors. By comparing the results of HT-XRD measurements under various atmospheres, and synchrotron radiation experiments, a reasonable interpretation of the XRD patterns collected with synchrotron radiation was established. It was revealed that trivalent Sc, with a radius comparable with that of tetravalent Zr cations, only occupied the B-site of $\mathrm{BaZrO}_{3}$. However, relatively larger Eu, Sm and Dy cations occupied both the A and B-sites of $\mathrm{BaZrO}_{3}$, even the samples were slightly Ba-deficient. These results indicate clearly an increasing tendency towards A-site occupation for the rare earth cations in $\mathrm{BaZrO}_{3}$ with an increasing radius. 


\section{Acknowledgements}

This study was supported by the Industrial Technology Research Grant Program in 2006 from the New Energy and Industrial Technology Development Organization (NEDO) of Japan. Powder XRD analysis was performed at the SPring-8 synchrotron radiation facility (Hyogo, Japan) with the approval of the Japan Synchrotron Radiation Research Institute (JASRI) as industrial application proposal (No. 2010B1850). 


\section{References}

${ }^{1}$ Y. Yamazaki, R. Hernandez-Sanchez, and S. M. Haile, "High Total Proton Conductivity in Large-Grained Yttrium-doped Barium Zirconate,” Chem. Mater., 21 [13], 2755-62 (2009).

${ }^{2}$ D. Pergolesi, E. Fabbri, A. D’Epifanio, E.D. Bartolomeo, A. Tebano, S. Sanna, S. Licoccia, G. Balestrino, and E. Traversa,"High Proton Conduction in Grain-Boudary-Free Yttrium-Doped Barium Zirconate Films Grown by Pulsed Laser Deposition,” Nat. Mater., 9 [10] 846-52 (2010).

${ }^{3}$ D. Han, Y. Nose, K. Shinoda, and T. Uda, "Site Selectivity of Dopants in $\mathrm{BaZr}_{1-y} \mathrm{M}_{y} \mathrm{O}_{3-\delta}(\mathrm{M}=\mathrm{Sc}$, Y, Sm, Eu, Dy) and Measurement of Their Water Contents and Conductivities,” Solid State Ionics, 213 2-7 (2013).

${ }^{4}$ D. Han, T. Uda, Y. Nose, T. Okajima, H. Murata, I. Tanaka, and K. Shinoda, “Tetravalent Dysprosium in a Perovskite-Type Oxide,”Adv. Mater., 24 [15] 2051-3 (2012).

${ }^{5}$ A.K. Azad, C. Savaniu, S. Tao, S. Duval, P. Holtappels, R.M. Ibberson, and J.T.S. Irvine, "Structural Origins of the Differing Grain Conductivity Values in $\mathrm{BaZr}_{0.9} \mathrm{Y}_{0.1} \mathrm{O}_{2.95}$ and Indication of Novel Approach to Counter Defect Association,” J. Mater. Chem. 18 [29] 3414-8 (2008).

6 Y. Yamazaki, R. Hernandez-Sanchez, and S.M. Haile, "Cation Non-stoichiometry in Yttrium-doped Barium Zirconate: Phase Behavior, Microstructure, and Proton Conductivity”J. Mater. Chem., 20 [37] 8158-66 (2010).

${ }^{7}$ D. Han, K. Kishida, K. Shinoda, H. Inui, and T. Uda, “A Comprehensive Understanding of Structure and Site Occupancy of Y in Y-Doped BaZrO3,” J. Mater. Chem. A, 1 [9] 3027-33 
(2013).

${ }^{8}$ T. Norby, M. Widerøe, R. Glöckner, and Y. Larring, “Hydrogen in Oxides,” Dalton Trans., 19 3012-8 (2004)

${ }^{9}$ F. Giannici, M. Shirpour, A. Longo, A. Martorana, R. Merkle, and J. Maier, "Long-Range and Short-Range Structure of Protn-Conducting Y: BaZrO3,” Chem. Mater., 23 [11] 2994-3002 (2011).

${ }^{10}$ S. Yamaguchi, and N. Yamada, "Thermal Lattice Expansion Behavior of Yb-Doped BaCeO3," Solid State Ionics., 162-163 23-9 (2004).

11 D. Han, M. Majima, and T. Uda, "Structure Analysis of $\mathrm{BaCe}_{0.8} \mathrm{Y}_{0.2} \mathrm{O}_{3-\delta}$ in Dry and Wet Atmospheres by High-Temperature X-ray Diffraction Measurement” J. Solid State Chem., 205 $122-128$ (2013).

12 C. Hiraiwa, D. Han, A. Kuramitsu, A. Kuwabara, H. Takeuchi, M. Majima, and T. Uda, “Chemical Expansion and Change in Lattice Constant of Y-Doped $\mathrm{BaZrO}_{3}$ by Hydration / Dehydration Reaction and Final Heat-Treating Temperature” J. Am. Ceram. Soc., 96 [3] 879-84 (2013).

${ }^{13}$ F.G. Kinyanjui, S.T. Norberg, I. Ahmed, S.G. Eriksson, and S. Hull, "In-situ Conductivity and Hydration Studies of Proton Conductors Using Neutron Powder Diffraction,” Solid State Ionics, 225 312-6 (2012).

${ }^{14}$ S. Imashuku, T. Uda, Y. Nose, and Y. Awakura, "Phase Relationship of the $\mathrm{BaO}-\mathrm{ZrO}_{2}-\mathrm{YO}_{1.5}$ 
System at 1500 and $1600{ }^{\circ} \mathrm{C}, ”$ J. Phase Equilib. Diff., 31 [4] 348-56 (2010).

${ }^{15}$ K.D. Kreuer, St. Adams, W. Münch, A. Fuchs, U. Klock, and J. Maier, "Proton Conducting Alkaline Earth Zirconates and Titanates for High Drain Electrochemical Applications,” Solid State Ionics, 145 [1-4] 295-306 (2001).

16 O. Knop, and J.S. Carlow, "Revision of the Shannon and Prewitt Effective Ionic Radii of Tetravalent Elements,” Can. J. Chem., 52 [12] 2175-83 (1974).

${ }^{17}$ R.D. Shannon, "Revised Effective Ionic Radii and Systematic Studies of Interatomic Distances in Halides and Chalcogenides,” Acta Crystallogr. A, 32 751-67 (1976). 


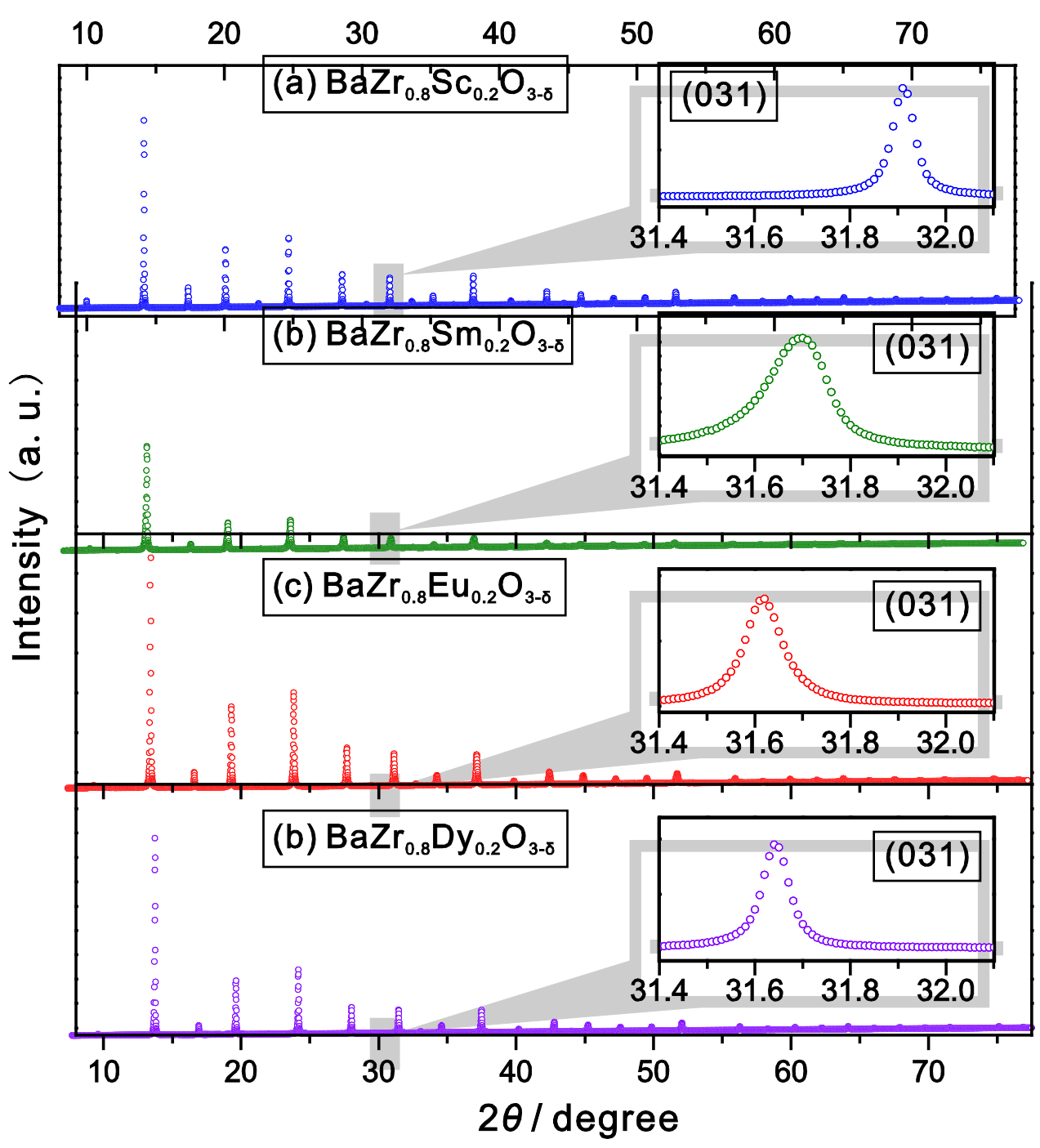

Fig. 1. XRD patterns of (a) $\mathrm{BaZr}_{0.8} \mathrm{Sc}_{0.2} \mathrm{O}_{3-\delta}$, (b) $\mathrm{BaZr}_{0.8} \mathrm{Sm}_{0.2} \mathrm{O}_{3-\delta}$, (c) $\mathrm{BaZr}_{0.8} \mathrm{Eu}_{0.2} \mathrm{O}_{3-\delta}$, and (d) $\mathrm{BaZr}_{0.8} \mathrm{Dy}_{0.2} \mathrm{O}_{3-\delta}$ collected with synchrotron radiation $(17.026 \mathrm{keV}) . \quad$ (031) diffraction peak profiles are highlighted in insets as an example. All the samples were quenched to room temperature after the heat-treatment at $1600{ }^{\circ} \mathrm{C}$. 


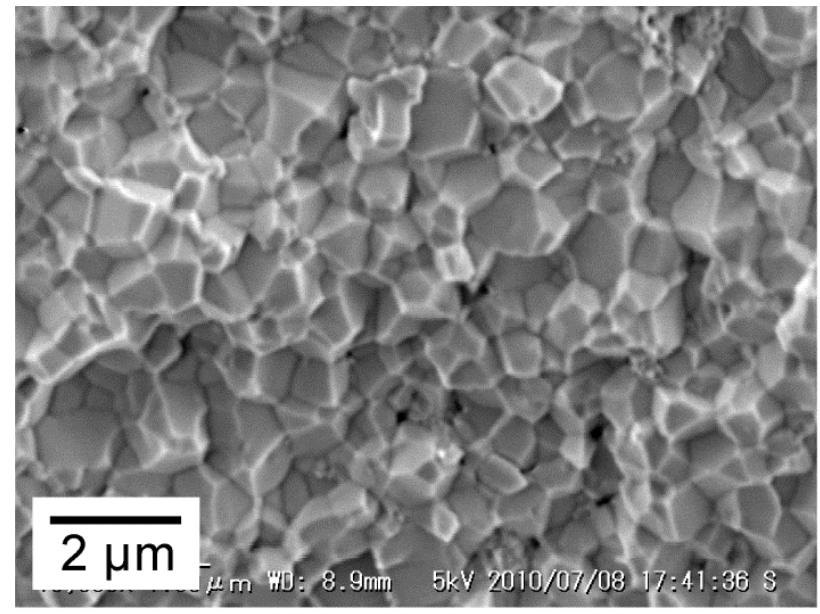

(a) $\mathrm{BaZr}_{0.8} \mathrm{Sc}_{0.2} \mathrm{O}_{3-\delta}$

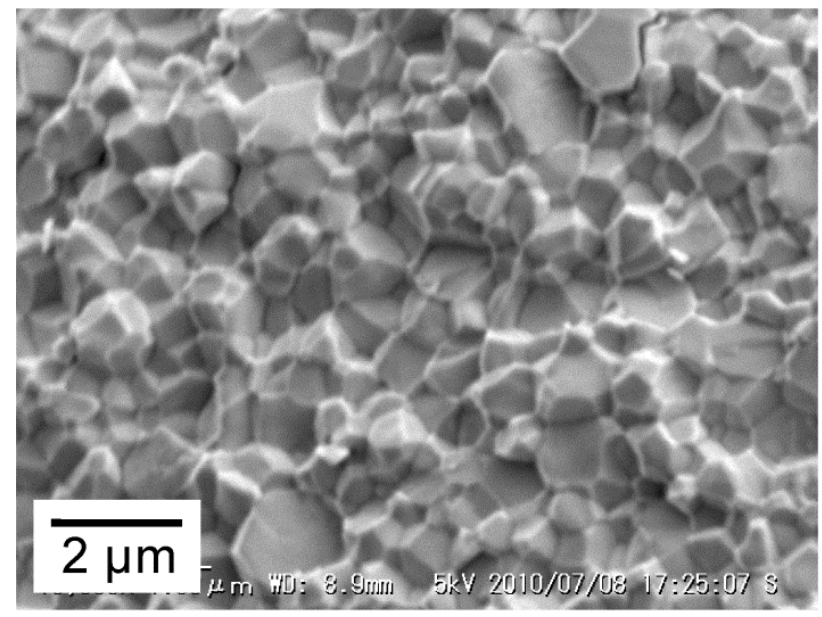

(c) $\mathrm{BaZr}_{0.8} \mathrm{Eu}_{0.2} \mathrm{O}_{3-\delta}$

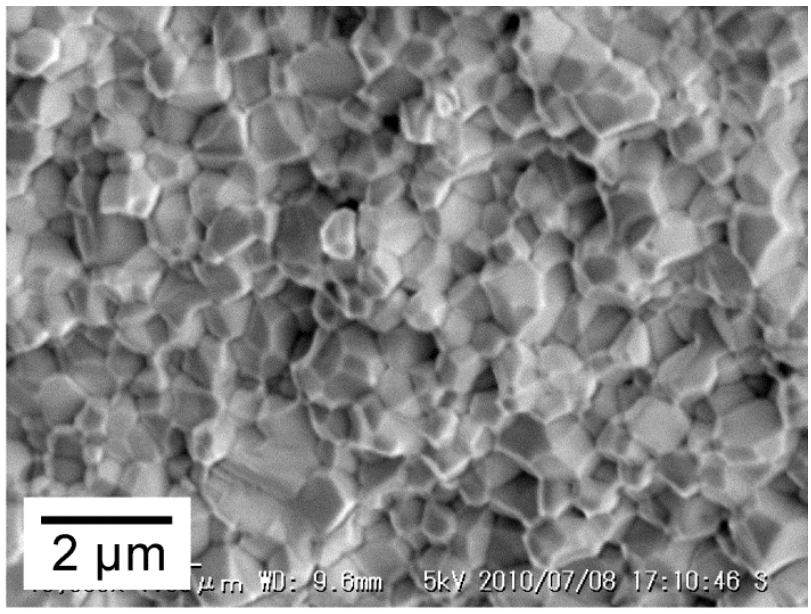

(b) $\mathrm{BaZr}_{0.8} \mathrm{Sm}_{0.2} \mathrm{O}_{3-\delta}$

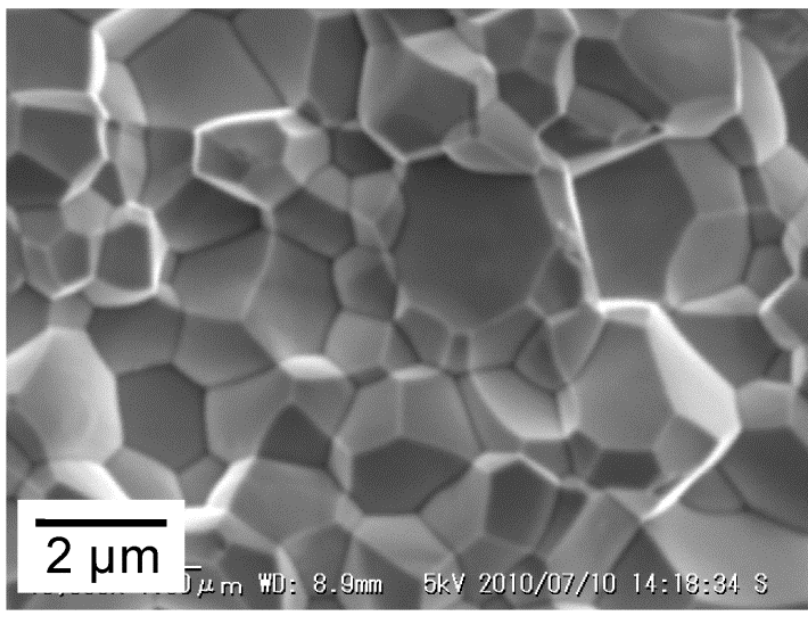

(d) $\mathrm{BaZr}_{0.8} \mathrm{Dy}_{0.2} \mathrm{O}_{3-\delta}$

Fig. 2. SEM images of fractured cross-sections of (a) $\mathrm{BaZr}_{0.8} \mathrm{Sc}_{0.2} \mathrm{O}_{3-\delta}$, (b) $\mathrm{BaZr}_{0.8} \mathrm{Sm}_{0.2} \mathrm{O}_{3-\delta}$, (c) $\mathrm{BaZr}_{0.8} \mathrm{Eu}_{0.2} \mathrm{O}_{3-\delta}$, and (d) $\mathrm{BaZr}_{0.8} \mathrm{Dy}_{0.2} \mathrm{O}_{3-\delta}$. All the samples were quenched to room temperature after the heat-treatment at $1600{ }^{\circ} \mathrm{C}$. 


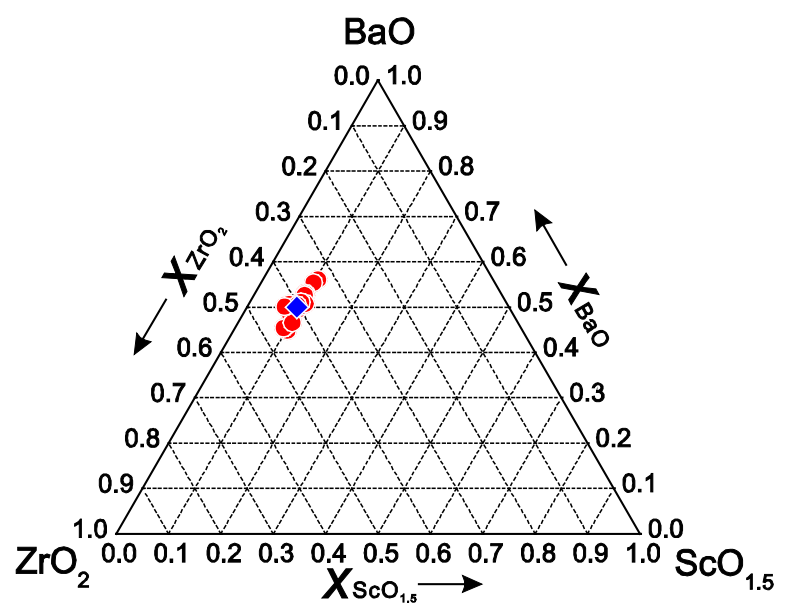

(a) $\mathrm{BaZr}_{0.8} \mathrm{Sc}_{0.2} \mathrm{O}_{3-\delta}$

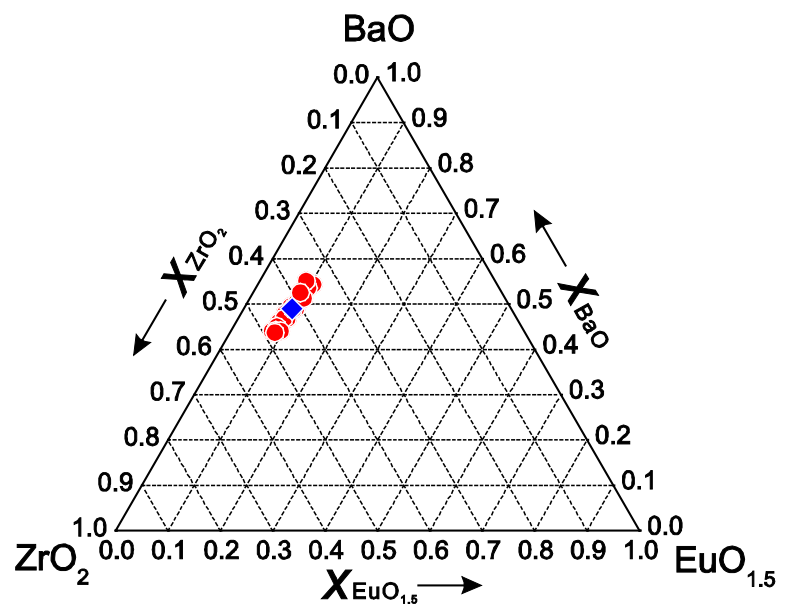

(c) $\mathrm{BaZr}_{0.8} \mathrm{Eu}_{0.2} \mathrm{O}_{3-\delta}$

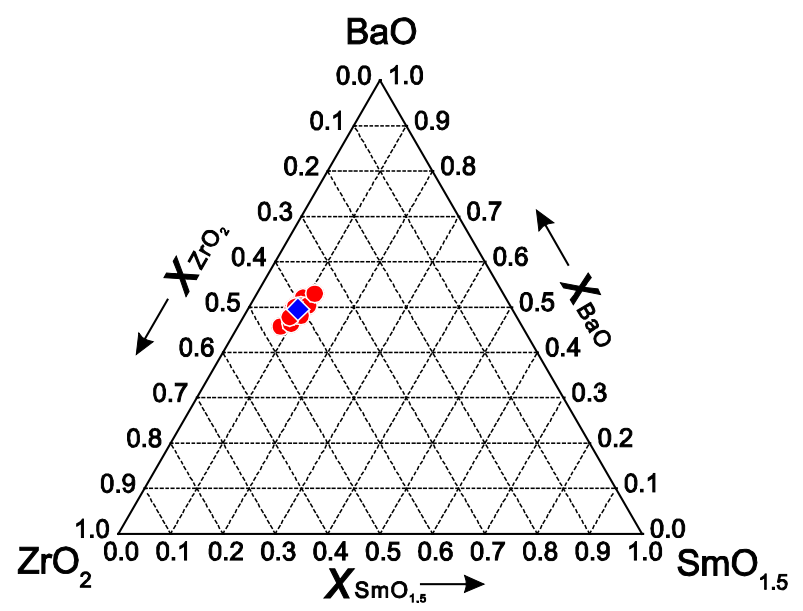

(b) $\mathrm{BaZr}_{0.8} \mathrm{Sm}_{0.2} \mathrm{O}_{3-\delta}$

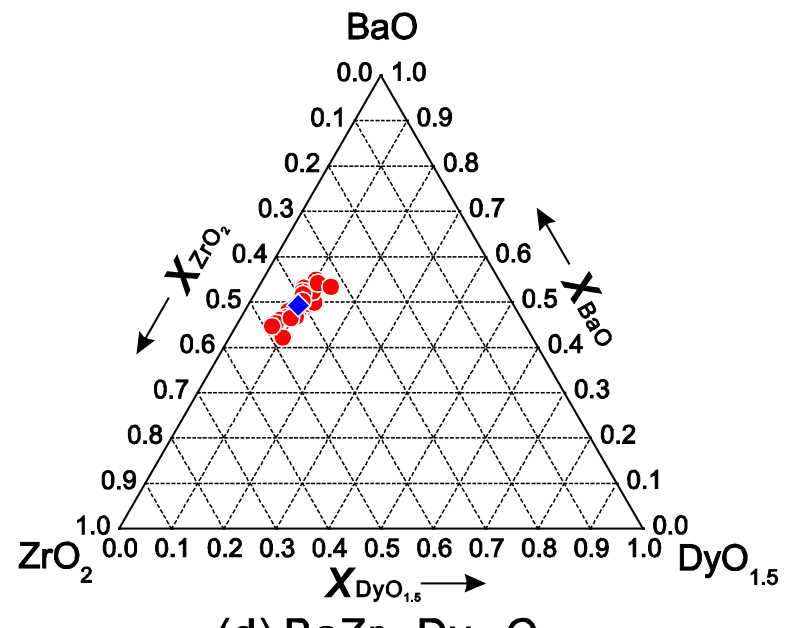

(d) $\mathrm{BaZr}_{0.8} \mathrm{Dy}_{0.2} \mathrm{O}_{3-\delta}$

Fig. 3. SEM-EDS composition analysis (O) of (a) $\mathrm{BaZr}_{0.8} \mathrm{Sc}_{0.2} \mathrm{O}_{3-\delta}$, (b) $\mathrm{BaZr}_{0.8} \mathrm{Sm}_{0.2} \mathrm{O}_{3-\delta}$, (c) $\mathrm{BaZr}_{0.8} \mathrm{Eu}_{0.2} \mathrm{O}_{3-\delta}$, and (d) $\mathrm{BaZr}_{0.8} \mathrm{Dy}_{0.2} \mathrm{O}_{3-\delta .}$. Total compositions determined by ICP-AES are marked 


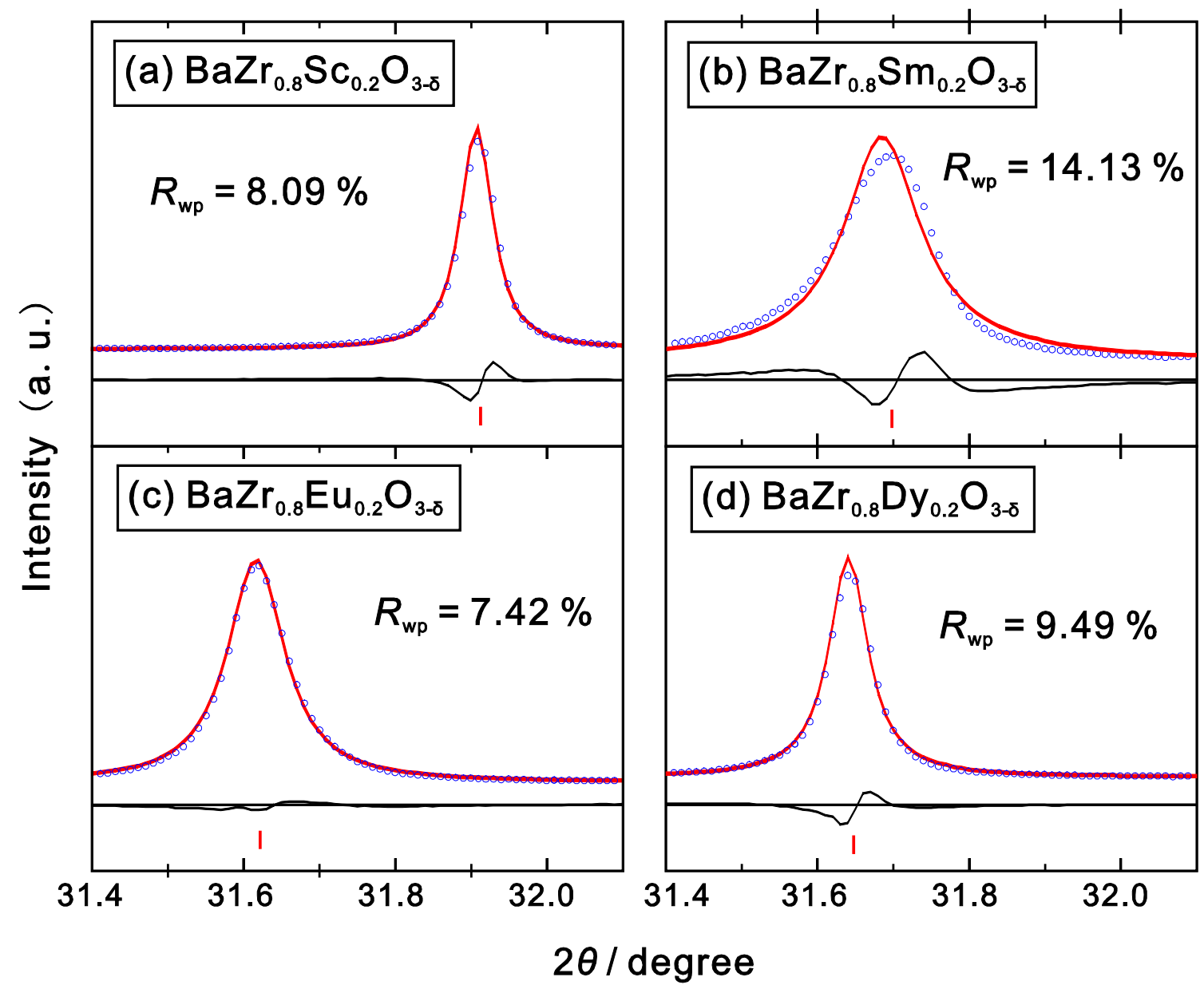

Fig. 4. Rietveld refinements of the (031) diffraction peaks of (a) $\mathrm{BaZr}_{0.8} \mathrm{Sc}_{0.2} \mathrm{O}_{3-\delta}$, (b) $\mathrm{BaZr}_{0.8} \mathrm{Sm}_{0.2} \mathrm{O}_{3-\delta}$, (c) $\mathrm{BaZr}_{0.8} \mathrm{Eu}_{0.2} \mathrm{O}_{3-\delta}$, and (d) $\mathrm{BaZr}_{0.8} \mathrm{Dy}_{0.2} \mathrm{O}_{3-\delta}$. All the samples were quenched to room temperature after the heat-treatment at $1600{ }^{\circ} \mathrm{C}$. The diffraction patterns were collected with synchrotron radiation (17.026 keV). A single cubic perovskite ( $P m \overline{3} m$ ) structure model was adopted. The observed profile (blue circle), calculated profile (red line), difference (black line at bottom), and Bragg peaks of candidate phases (vertical lines) are shown. 


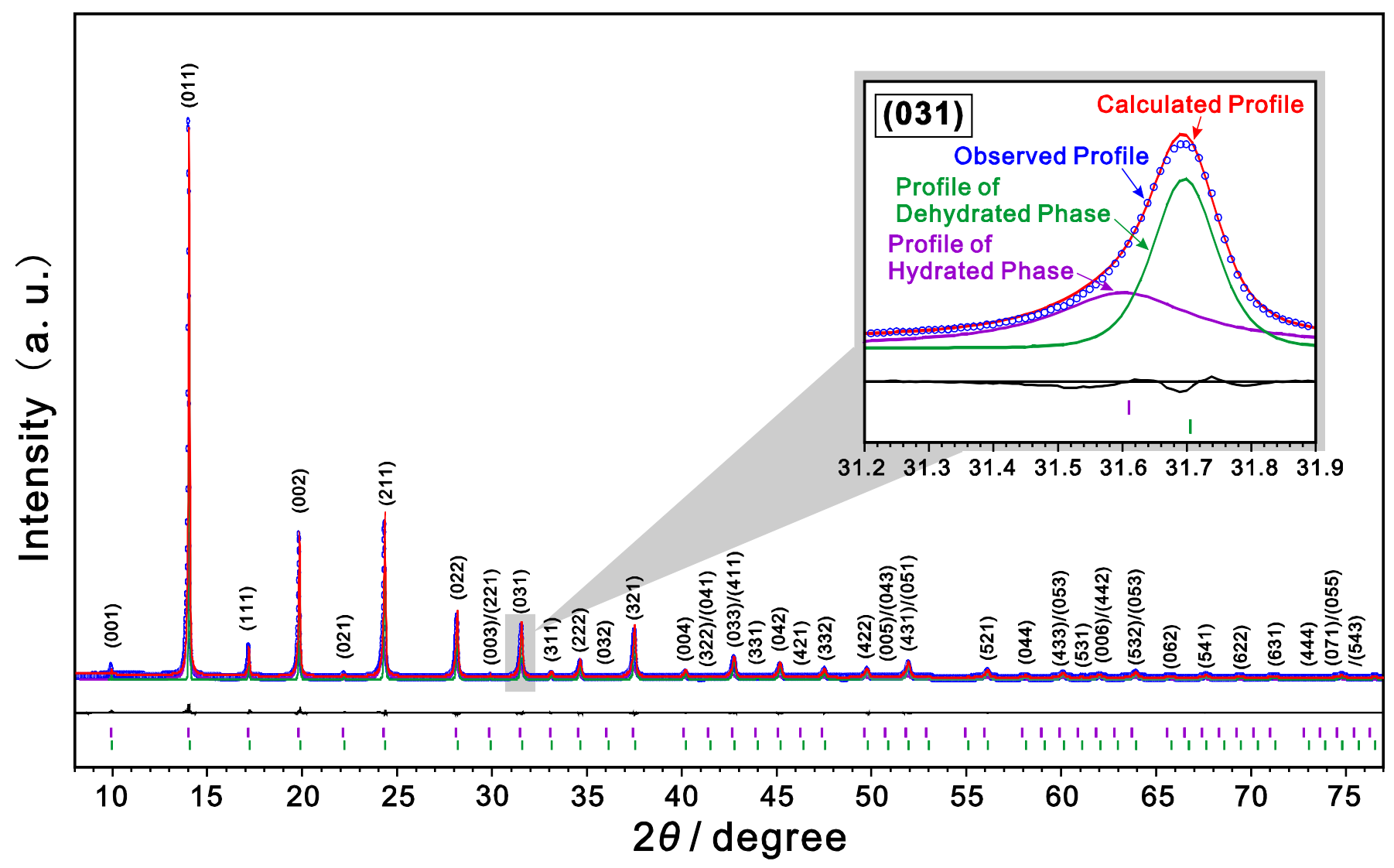

Fig. 5. Rietveld refinement of the diffraction pattern of $\mathrm{BaZr}_{0.8} \mathrm{Sm}_{0.2} \mathrm{O}_{3-\delta}$ collected with synchrotron radiation (17.026 keV). The sample were quenched to room temperature after the heat-treatment at $1600{ }^{\circ} \mathrm{C}$. Two cubic perovskite ( $P m \overline{3} m$ ) structure models for hydrated and dehydrated phases were adopted for the refinement. Fitting of the (031) diffraction peak profile is highlighted in the inset. Observed profile (blue circle), calculated profile (red line), difference (black line at bottom), and Bragg peaks of candidate phases (vertical lines) are shown. 


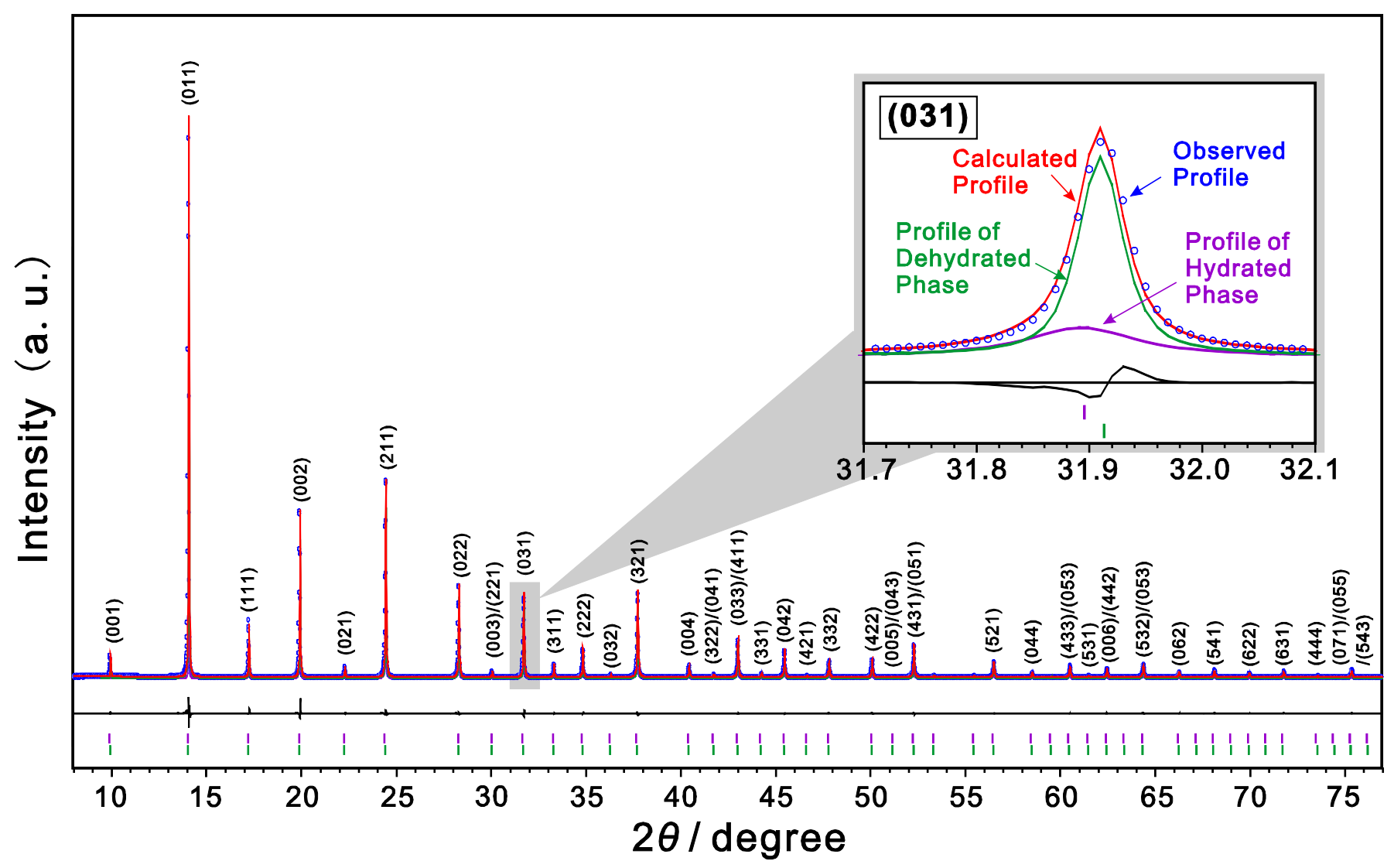

Fig. 6. Rietveld refinement of the diffraction pattern of $\mathrm{BaZr}_{0.8} \mathrm{Sc}_{0.2} \mathrm{O}_{3-\delta}$ collected with synchrotron radiation (17.026 keV). The sample were quenched to room temperature after the heat-treatment at $1600{ }^{\circ} \mathrm{C}$. Two cubic perovskite ( $P m \overline{3} m$ ) structure models for hydrated and dehydrated phases were adopted for the refinement. Fitting of the (031) diffraction peak profile is highlighted in the inset. Observed profile (blue circle), calculated profile (red line), difference (black line at bottom), and Bragg peaks of candidate phases (vertical lines) are shown. 


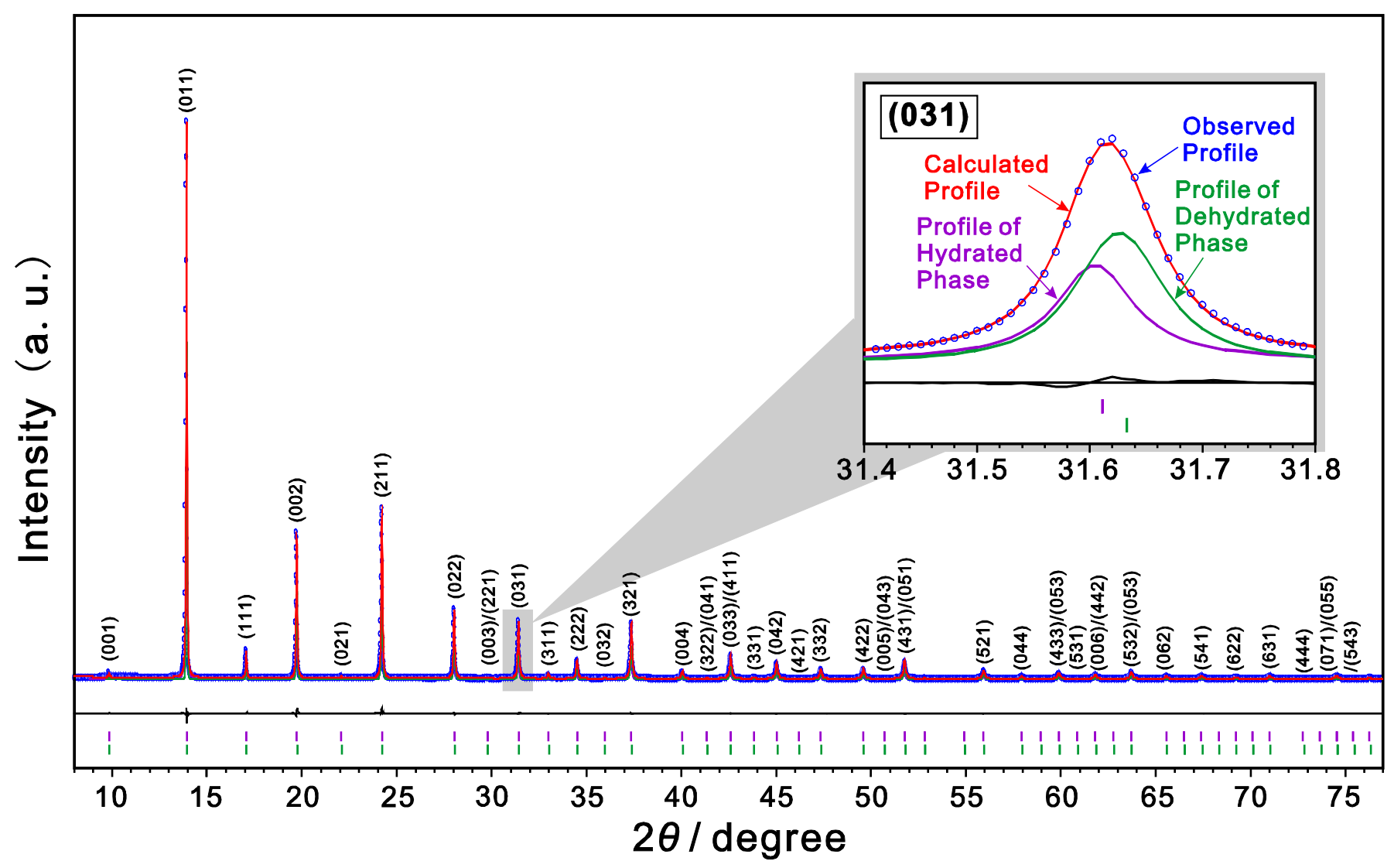

Fig. 7. Rietveld refinement of the diffraction pattern of $\mathrm{BaZr}_{0.8} \mathrm{Eu}_{0.2} \mathrm{O}_{3-\delta}$ collected with synchrotron radiation (17.026 keV). The sample were quenched to room temperature after the heat-treatment at $1600{ }^{\circ} \mathrm{C}$. Two cubic perovskite ( $P m \overline{3} m$ ) structure models for hydrated and dehydrated phases were adopted for the refinement. Fitting of the (031) diffraction peak profile is highlighted in the inset. Observed profile (blue circle), calculated profile (red line), difference (black line at bottom), and Bragg peaks of candidate phases (vertical lines) are shown. 


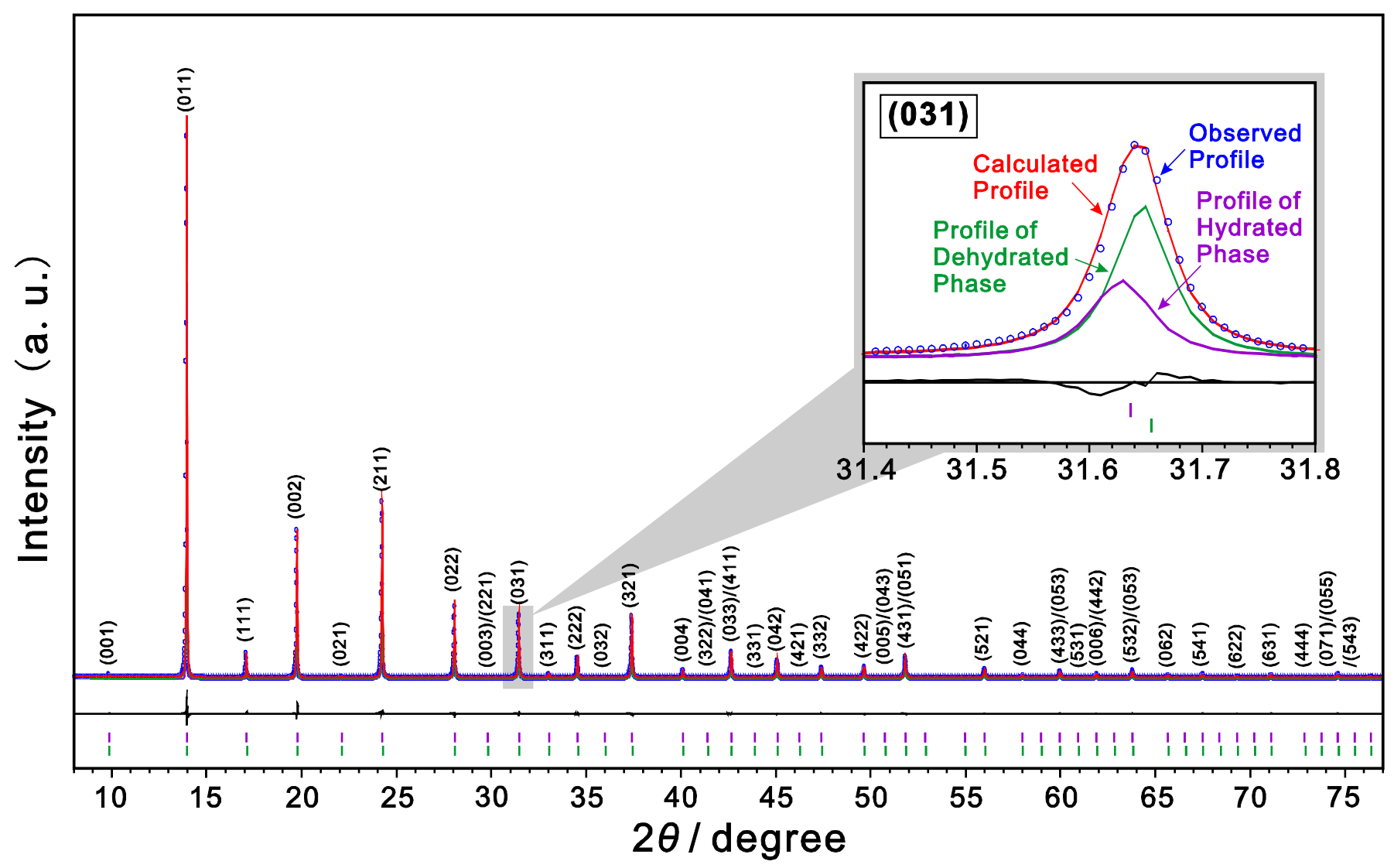

Fig. 8. Rietveld refinement of the diffraction pattern of $\mathrm{BaZr}_{0.8} \mathrm{Dy}_{0.2} \mathrm{O}_{3-\delta}$ collected with synchrotron radiation (17.026 keV). The sample were quenched to room temperature after the heat-treatment at $1600{ }^{\circ} \mathrm{C}$. Two cubic perovskite ( $P m \overline{3} m$ ) structure models for hydrated and dehydrated phases were adopted for the refinement. Fitting of the (031) diffraction peak profile is highlighted in the inset. Observed profile (blue circle), calculated profile (red line), difference (black line at bottom), and Bragg peaks of candidate phases (vertical lines) are shown. 


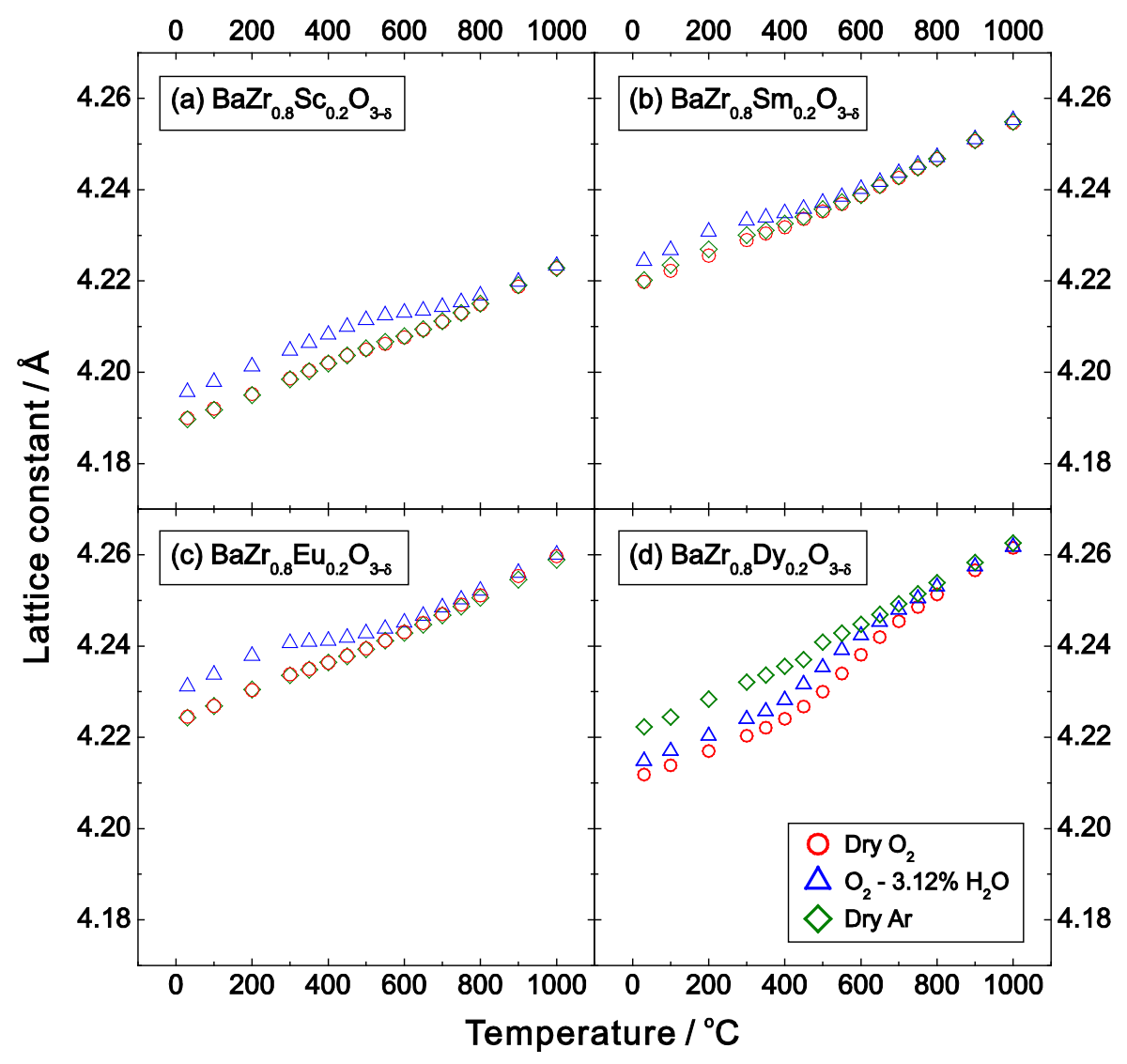

Fig. 9. Variation of lattice constants of (a) $\mathrm{BaZr}_{0.8} \mathrm{Sc}_{0.2} \mathrm{O}_{3-\delta}$, (b) $\mathrm{BaZr}_{0.8} \mathrm{Sm}_{0.2} \mathrm{O}_{3-\delta}$, (c)

$\mathrm{BaZr}_{0.8} \mathrm{Eu}_{0.2} \mathrm{O}_{3-\delta}$, and (d) $\mathrm{BaZr}_{0.8} \mathrm{Dy}_{0.2} \mathrm{O}_{3-\delta}$ in dry $\mathrm{O}_{2}, \mathrm{O}_{2}-3.12 \% \mathrm{H}_{2} \mathrm{O}$, and dry Ar with temperature.

All the samples were quenched to room temperature after the heat-treatment at $1600{ }^{\circ} \mathrm{C}$. 


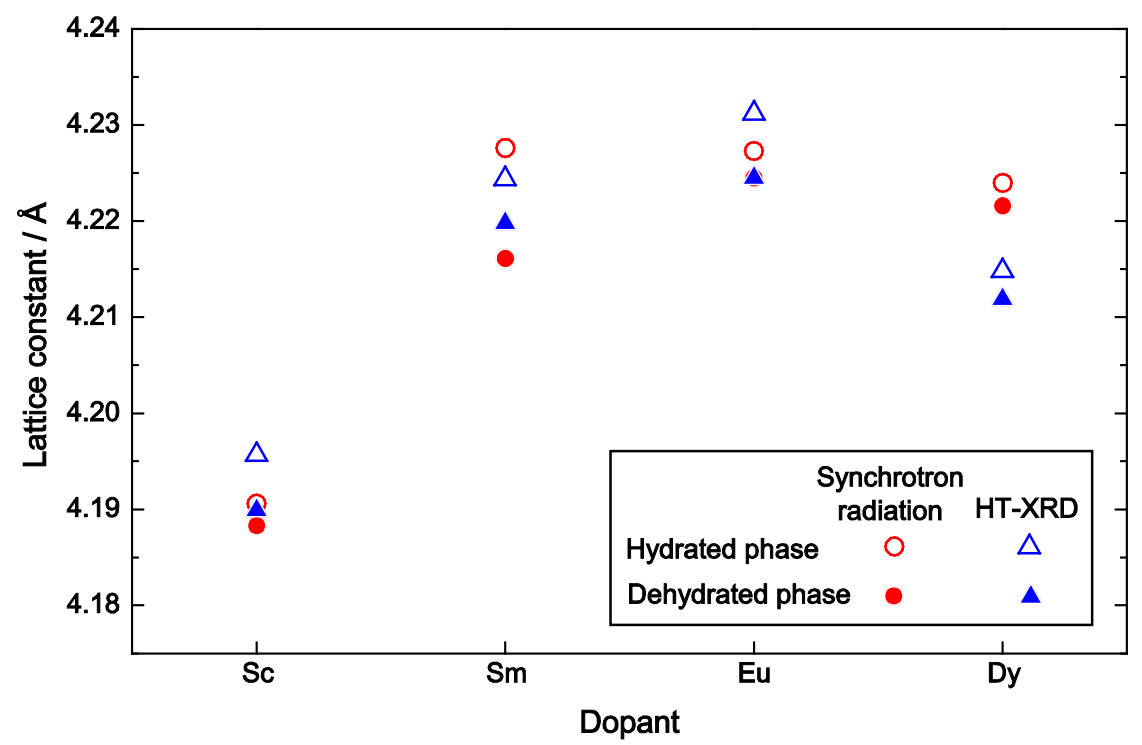

Fig. 10. Lattice constants of hydrated and dehydrated phases in $\mathrm{BaZr}_{0.8} \mathrm{M}_{0.2} \mathrm{O}_{3-\delta}(\mathrm{M}=\mathrm{Sc}, \mathrm{Sm}$, Eu,

Dy) determined by Rietveld refinements using the diffraction patterns collected in HT-XRD measurements at $30{ }^{\circ} \mathrm{C}$ in dry and wet $\mathrm{O}_{2}$ (see Table 2), and synchrotron radiation experiments (see Table 1). All the samples were quenched to room temperature after the heat-treatment at $1600{ }^{\circ} \mathrm{C}$. 
Table 1. Rietveld refinement results of the diffraction patterns of $\mathrm{BaZr}_{0.8} \mathrm{M}_{0.2} \mathrm{O}_{3-\delta}(\mathrm{M}=\mathrm{Sc}$, Sm, Eu, Dy) collected with synchrotron radiation (17.026 $\mathrm{keV})$. The structures of all the phases were assigned to be cubic ( $P m \overline{3} m)$. All the samples were quenched to room temperature after the heat-treatment at $1600{ }^{\circ} \mathrm{C}$.

\begin{tabular}{|c|c|c|c|c|c|c|c|c|c|c|c|}
\hline \multirow{3}{*}{$\begin{array}{l}\text { Nominal sample } \\
\text { composition }\end{array}$} & \multirow{3}{*}{$\begin{array}{l}R_{\mathrm{wp}} \\
/ \%\end{array}$} & \multirow{3}{*}{$\chi^{2}$} & \multirow{3}{*}{ Phase (composition) } & \multirow{3}{*}{$\begin{array}{c}\text { Lattice } \\
\text { constant / } \\
\AA\end{array}$} & \multirow{3}{*}{$\begin{array}{c}\text { Fraction / } \\
\text { wt\% }\end{array}$} & \multicolumn{4}{|c|}{ Site occupancy } & \multirow{2}{*}{\multicolumn{2}{|c|}{$\begin{array}{l}\text { Equivalent isotropic } \\
\text { temperature factor / } \\
\AA^{2}\end{array}$}} \\
\hline & & & & & & \multicolumn{2}{|c|}{ A-site } & \multicolumn{2}{|c|}{ B-site } & & \\
\hline & & & & & & $\mathrm{Ba}$ & M & $\mathrm{Zr}$ & M & A-site & B-site \\
\hline \multirow{2}{*}{$\mathrm{BaZr}_{0.8} \mathrm{Sc}_{0.2} \mathrm{O}_{3-\delta}$} & \multirow{2}{*}{6.74} & \multirow{2}{*}{4.09} & $\begin{array}{c}\text { Dehydrated phase } \\
\left(\mathrm{Ba}_{1.00} \mathrm{Zr}_{0.81} \mathrm{Sc}_{0.19} \mathrm{O}_{3-\delta}\right)\end{array}$ & 4.1883(1) & 76.18 & $1.000(2)$ & $0.000(2)$ & $0.810(2)$ & $0.190(2)$ & $0.78(1)$ & $0.53(2)$ \\
\hline & & & $\begin{array}{c}\text { Hydrated phase } \\
\left(\mathrm{Ba}_{1.00} \mathrm{Zr}_{0.81} \mathrm{Sc}_{0.19} \mathrm{O}_{3-\delta}\right)\end{array}$ & $4.1906(2)$ & 23.82 & $1.000(2)$ & $0.000(2)$ & $0.810(2)$ & $0.190(2)$ & $0.72(6)$ & $0.20(7)$ \\
\hline \multirow{2}{*}{$\mathrm{BaZr}_{0.8} \mathrm{Sm}_{0.2} \mathrm{O}_{3-\delta}$} & \multirow{2}{*}{6.60} & \multirow{2}{*}{4.12} & $\begin{array}{c}\text { Dehydrated phase } \\
\left(\mathrm{Ba}_{0.98} \mathrm{Zr}_{0.81} \mathrm{Sm}_{0.19} \mathrm{O}_{3-\delta}\right)\end{array}$ & $4.2161(1)$ & 52.12 & $0.990(2)$ & $0.010(2)$ & $0.818(2)$ & $0.182(2)$ & $0.80(3)$ & $0.80(3)$ \\
\hline & & & $\begin{array}{c}\text { Hydrated phase } \\
\left(\mathrm{Ba}_{0.98} \mathrm{Zr}_{0.81} \mathrm{Sm}_{0.19} \mathrm{O}_{3-\delta}\right)\end{array}$ & $4.2276(3)$ & 47.88 & $0.990(3)$ & $0.010(3)$ & $0.818(3)$ & $0.182(3)$ & $0.80(10)$ & $0.80(10)$ \\
\hline \multirow{2}{*}{$\mathrm{BaZr}_{0.8} \mathrm{Eu}_{0.2} \mathrm{O}_{3-\delta}$} & \multirow{2}{*}{5.45} & \multirow{2}{*}{3.61} & $\begin{array}{c}\text { Dehydrated phase } \\
\left(\mathrm{Ba}_{0.96} \mathrm{Zr}_{0.82} \mathrm{Eu}_{0.18} \mathrm{O}_{3-\delta}\right)\end{array}$ & $4.2245(1)$ & 56.14 & $0.973(1)$ & $0.013(1)$ & $0.831(5)$ & $0.169(5)$ & $0.80(9)$ & $0.70(9)$ \\
\hline & & & $\begin{array}{c}\text { Hydrated phase } \\
\left(\mathrm{Ba}_{0.96} \mathrm{Zr}_{0.82} \mathrm{Eu}_{0.18} \mathrm{O}_{3-\delta}\right)\end{array}$ & $4.2273(1)$ & 43.86 & $0.973(1)$ & $0.013(1)$ & $0.831(5)$ & $0.169(5)$ & $0.80(13)$ & $0.43(13)$ \\
\hline \multirow{2}{*}{$\mathrm{BaZr}_{0.8} \mathrm{Dy}_{0.2} \mathrm{O}_{3-\delta}$} & \multirow{2}{*}{7.54} & \multirow{2}{*}{4.57} & $\begin{array}{c}\text { Dehydrated phase } \\
\left(\mathrm{Ba}_{0.97} \mathrm{Zr}_{0.81} \mathrm{Dy}_{0.19} \mathrm{O}_{3-\delta}\right)\end{array}$ & $4.2216(1)$ & 75.71 & $0.975(1)$ & $0.005(1)$ & $0.814(1)$ & $0.186(1)$ & $0.80(5)$ & $0.64(5)$ \\
\hline & & & $\begin{array}{c}\text { Hydrated phase } \\
\left(\mathrm{Ba}_{0.97} \mathrm{Zr}_{0.81} \mathrm{Dy}_{0.19} \mathrm{O}_{3-\delta}\right)\end{array}$ & $4.2240(1)$ & 24.29 & $0.975(1)$ & $0.005(1)$ & $0.814(1)$ & $0.186(1)$ & $0.80(2)$ & $0.20(2)$ \\
\hline
\end{tabular}


Table 2. Lattice constant of $\mathrm{BaZr}_{0.8} \mathrm{M}_{0.2} \mathrm{O}_{3-\delta}\left(\mathrm{M}=\mathrm{Sc}, \mathrm{Sm}\right.$, Eu, Dy) at $30{ }^{\circ} \mathrm{C}$ in various atmospheres.

All the samples were quenched to room temperature after the heat-treatment at $1600{ }^{\circ} \mathrm{C}$.

\begin{tabular}{|c|c|c|c|}
\hline \multirow{4}{*}{$\begin{array}{c}\text { Nominal sample } \\
\text { composition }\end{array}$} & \multicolumn{3}{|c|}{ Lattice constant / $\AA$} \\
\hline & \multicolumn{3}{|c|}{ Wet $\mathrm{O}_{2}$} \\
\hline & Dry $\mathrm{O}_{2}$ & & Dry Ar \\
\hline & \multicolumn{3}{|c|}{$\left(p_{\mathrm{H}_{2} \mathrm{O}}=0.0312 \mathrm{~atm}\right)$} \\
\hline $\mathrm{BaZr}_{0.8} \mathrm{Sc}_{0.2} \mathrm{O}_{3-\delta}$ & 4.1899(1) & $4.1957(1)$ & 4.1897(1) \\
\hline $\mathrm{BaZr}_{0.8} \mathrm{Sm}_{0.2} \mathrm{O}_{3-\delta}$ & $4.2200(2)$ & $4.2244(2)$ & $4.2202(2)$ \\
\hline $\mathrm{BaZr}_{0.8} \mathrm{Eu}_{0.2} \mathrm{O}_{3-\delta}$ & $4.2245(1)$ & $4.2312(2)$ & $4.2243(1)$ \\
\hline $\mathrm{BaZr}_{0.8} \mathrm{Dy}_{0.2} \mathrm{O}_{3-\delta}$ & $4.2119(1)$ & $4.2148(1)$ & $4.2223(1)$ \\
\hline
\end{tabular}

